\title{
Análise geoestatística do "vira-cabeça" na cultura do tomateiro
}

\author{
Waylson Zancanella Quartezani ${ }^{1}$, Leonardo Raasch Hell ${ }^{2}$, Jadier de Oliveira Cunha Junior ${ }^{3}$, Willian Bucker Moraes ${ }^{4}$, \\ Leônidas Leoni Belan ${ }^{4}$, Simone de Paiva Caetano Bucker Moraes ${ }^{4}$, Waldir Cintra de Jesus Junior ${ }^{5}$, Edson Luiz Furtado ${ }^{6}$
} ${ }^{1}$ IFES: Instituto Federal de Educação, Ciência e Tecnologia do Espírito Santo - Campus Montanha. CEP: 29890-000, Montanha, ES, waylson.
quartezani@ifes.edu.br; ${ }^{2}$ IFES: Instituto Federal de Educação, Ciência e Tecnologia do Espírito Santo - Campus Itapina. CEP: 29.709-910,
Colatina, ES, leonardoraaschhell@hotmail.com; ${ }^{3}$ IFES: Instituto Federal de Educação, Ciência e Tecnologia do Espírito Santo - Campus Itapina.
CEP: 29.709-910, Colatina, ES, jadier.cunha@ifes.edu.br; ${ }^{4}$ CCAE/UFES: Centro de Ciências Agrárias e Engenharias da Universidade Federal
do Espírito Santo. CEP: 29500-000, Alegre, ES, willian.moraes@ufes.br; leonidasbelan@gmail.com, simonepaiva01@hotmail.com; ${ }^{5}$ UFSCar
- Universidade Federal de São Carlos, Departamento Acadêmico Lagoa do Sino, Centro de Ciências da Natureza, CEP: 18290000 - Buri, SP;
wcintra@ufscar.br; ${ }^{6}$ FCA/UNESP: Faculdade de Ciências Agronômicas, Universidade Estadual Paulista "Julio de Mesquita Filho", CEP18610-
310, Botucatu, SP, elfurtado@fca.unesp.br

Autor para correspondência: Waylson Zancanella Quartezani (waylson.quartezani@ifes.edu.br)

Data de chegada: 23/05/2017. Aceito para publicação em: 16/08/2017.

$10.1590 / 0100-5405 / 180383$

\section{RESUMO}

Quartezani, W.Z.; Hell, L.R.; Cunha Junior, J.O.; Moraes, W.B.; Belan, L.L.; Moraes, S.P.C.B.; Jesus Junior, W.C.; Furtado, E.L. Análise geoestatística do "vira-cabeça" na cultura do tomateiro. Summa Phytopathologica, v.44, n.1, p.51-55, 2018.

Em relação às diversas doenças que reduzem a produção da cultura do tomateiro, destaca-se a ocorrência da virose conhecida como "vira-cabeça". Epidemias dessa doença são frequentes com altas taxas de progresso e danos significativos. Nesse caso, estudos sobre a variabilidade espaço-temporal podem auxiliar em propor estratégias de manejo. Portanto, o objetivo desse estudo foi mapear a distribuição espacial da incidência do "vira-cabeça" ao longo do tempo em lavoura de tomateiro, para entender os mecanismos de dispersão do patógeno e progresso da doença. Para isso, a presença ou ausência de sintomas da doença foi monitorada ao longo do tempo em 120 plantas georreferenciadas, dispostas em malha regular e distribuídos num espaçamento de $1,0 \times 0,5 \mathrm{~m}$. Os dados de incidência da doença foram submetidos à análise geoestatística. Após o ajuste dos semivariogramas foi realizada a interpolação dos dados por krigagem. Houve epidemia da doença na lavoura de tomate, e a taxa de progresso (Dy/Dt) variou de 4,7 a 6 plantas doentes/dia, e $100 \%$ das plantas apresentaram sintomas aos 20 dias após a primeira detecção da doença na lavoura. Houve dependência espacial forte da distribuição das plantas de tomateiro com sintomas de "vira-cabeça" em todas as avaliações, e valor de alcance variando de 4,3 a 1,69 m. Ao longo do tempo surgiram focos secundários da doença, expansão lateral e coalescência desses, caracterizando dispersão por ação do agente vetor associado às fontes de inóculo inicial, internas e externas à lavoura. O padrão aleatório de distribuição da doença evoluiu para agregado, e posteriormente regular.

Palavras-chave: TSWV; Solanum lycopersicum; krigagem, Espaço-temporal;

\section{ABSTRACT}

Quartezani, W.Z.; Hell, L.R.; Cunha Junior, J.O.; Moraes, W.B.; Belan, L.L.; Moraes, S.P.C.B.; Jesus Junior, W.C.; Furtado, E.L. Geostatistical analysis of tospovirus in tomato crop. Summa Phytopathologica, v.44, n.1, p.51-55, 2018.

Considering the various diseases that reduce tomato crop production, the virosis known as "vira-cabeça" is highlighted. Epidemics of this disease are frequent, showing high progress rates and expressive damage. In this case, studies about the space-time variability can help propose management strategies. Therefore, the aim this study was to map the spatial distribution of tospovirus incidence over time in a tomato crop in order to understand the dispersal mechanisms of this pathogen and the disease progress. Thus, the presence or the absence of symptoms of this disease was monitored over time in 120 georeferenced plants, arranged in a regular mesh and distributed in a spacing of $1.0 \times 0.5 \mathrm{~m}$. The disease incidence data were subjected to the geostatistical analysis. After the adjustment of semivariograms, interpolation of data was performed by means of kriging. There was epidemic of the disease in tomato crop, and the progress rate $(\mathrm{Dy} / \mathrm{Dt})$ varied from 4.7 to 6 diseased plants/day, while $100 \%$ plants exhibited symptoms at 20 days after the first detection of the disease on the crop. There was strong spatial dependence of the distribution of tomato plants with symptoms of "viracabeça" in all assessments, and the reach value varied from 4.3 to $1.69 \mathrm{~m}$. Over time, secondary foci of the disease emerged, as well as lateral expansion and coalescence of the latter, characterizing dispersion due to the action of the vector agent associated with initial inoculum sources, internal and external to the tomato crop. The random pattern of the disease distribution progressed to aggregated and subsequently regular.

Keywords: TSWV, Solanum lycopersicum, kriging, space-time.

O tomateiro (Solanum lycopersicum L.) é cultivado nas mais diferentes latitudes geográficas do planeta, sendo a segunda hortaliça mais produzida no mundo (06). Em 2011, a produção mundial foi de 159,02 milhões de toneladas de tomate, sendo China, Índia e Estados Unidos os principais produtores (06). O Brasil, oitavo produtor mundial, produziu 4.145.553 toneladas no ano de 2015, sendo o Estado do Espírito Santo responsável por 144.834 ton (14). No entanto, a produção brasileira está estimada em 3.519.199 ton para o ano de 2016, correspondendo à redução de $15,1 \%$ em relação ao ano anterior (14).

Variações anuais quanto à produção de tomate são reflexo do risco 
relacionado a essa cultura, devido principalmente a diversidade de ambientes de cultivo e ocorrência de pragas e doenças (19). Dentre os fatores que reduzem a produção do tomateiro (S. lycopersicum) destacam-se as doenças de natureza virótica. Nesse caso, os vírus do gênero Tospovirus, responsáveis por sintomas da doença conhecida como "vira-cabeça", provocam danos significativos à cultura, podendo reduzir em até $96,3 \%$ a produção de frutos comerciais por planta $(5,8)$, e em alguns casos limitar o plantio de cultivares suscetíveis em regiões de ocorrência do patógeno (7).

O gênero Tospovirus apresenta quatro espécies que infectam a cultura do tomateiro: TSWV (Tomato Spotted Wilt Virus), TCSV (Tomato chlorotic spot virus), o GRSV (Groundnut ringspot virus) (23), e INSV (Impatiens necrotic spot virus) que ainda não foi detectada no Brasil (15). Além da cultura do tomateiro, existem várias outras culturas com danos relacionados a tospoviroses, como por exemplo a cultura da alface, do pimentão e da abobrinha 'Casert' $(5,9,22)$. Esses níveis de danos e perdas são consequência da alta taxa de progresso da doença, relacionada à disseminação do patógeno realizada pelo inseto vetor Tripes (Thysanoptera). Uma vez adquirido o vírus, o vetor pode migrar e transmitir com eficiência o patógeno para plantas sadias (29).

Nesse contexto, estudos sobre dinâmica populacional, variabilidade espaço-temporal e epidemiologia de doenças de plantas podem auxiliar na adoção de estratégias e táticas de manejo mais eficazes e de menor impacto ambiental (24). Para tanto, faz-se o uso de ferramentas espaciais como a geoestatística e a krigagem para obter mapas da distribuição da doença no espaço e no tempo. A geoestatística tem sido eficientemente aplicada para estudar a distribuição espacial de doenças (1). Essa ferramenta permite quantificar a magnitude e o grau de dependência espacial e descrever a variabilidade espacial das variáveis (28). Portanto, o objetivo desse estudo foi mapear a distribuição espacial da incidência do "vira-cabeça" ao longo do tempo em lavoura de tomateiro, para entender os mecanismos de dispersão do patógeno e progresso da doença.

\section{MATERIAIS E MÉTODOS}

O estudo foi realizado no setor de horticultura do Instituto Federal do Espírito Santo (IFES) - Campus Itapina, região Noroeste do Espírito Santo. A região caracteriza-se por predominar o clima tropical seco do tipo Aw, com altitude de $70 \mathrm{~m}$, latitude $19^{\circ} 30^{\prime}$ Sul e longitude $40^{\circ}$ 20' Oeste.

\section{Lavoura experimental}

O experimento foi conduzido no verão em lavoura de tomate da cultivar "Santa Clara", suscetível ao "vira-cabeça", plantada com espaçamento regular de 1,0 m entre linhas e 0,5 m entre plantas. As mudas foram transplantadas para o campo aos 25 dias após a semeadura, quando apresentaram cinco pares de folhas definitivas. As plantas foram conduzidas com uma haste e tutoramento vertical. A irrigação foi realizada a cada três dias de forma localizada com auxílio de mangueira. Os demais tratos culturais foram executados de acordo com as recomendações para a cultura, realizando a correção da acidez do solo e adubações de acordo com as indicações técnicas.

\section{Grade amostral e avaliações da doença}

Foi determinada malha amostral regular com 120 pontos, distribuídos num espaçamento de 1,0 x 0,5 m, conforme espaçamento da lavoura. Cada ponto amostral foi composto por um tomateiro.
Considerando o espaçamento da cultura, foi realizado o referencimento das plantas em sistema de coordenadas (x;y). Para tanto, foi considerado o vértice inferior esquerdo da parcela como coordenada $(0 ; 0)$, e dessa forma, para a planta localizada na primeira linha e primeira coluna foi dada a coordenada $(0 ; 0)$.

Após a manifestação dos primeiros sintomas da doença nas plantas, foram realizadas avaliações visuais em todas as plantas da lavoura para registrar a presença ou ausência de sintomas da doença. Assim, foram realizadas cinco avaliações, com intervalo de cinco dias entre elas, sendo essas aos 57, 62, 67, 72 e 77 dias após o transplantio (DAP). Após este período foi registrado $100 \%$ de plantas doentes na lavoura e, portanto, encerradas as avaliações. Conforme proposto por Gomes et al. (12) as avaliações foram realizadas por diagnose visual dos sintomas característicos da virose: redução geral do porte da planta, enfezamento, curvamento do ponteiro virado para baixo e lesões necróticas nas hastes. A localização das plantas sadias e doentes em cada avaliação determinou uma malha amostral referente à distribuição da doença no canteiro ao longo do tempo.

Esses dados foram utilizados para calcular as taxas absolutas de progresso (dy/dt) do "vira-cabeça", utilizando-se os valores de incidência (percentual de plantas com sintomas) no tempo (DAP).

\section{Análise geoestatística}

Os dados foram tabulados na forma de dados binários, ou seja as plantas com e sem a incidência da doença receberam as notas 1 (um) e 0 (zero), respectivamente. Esses dados binários (presença ou ausência da doença) foram utilizados para a análise geoestatística, no intuito de verificar a existência e, quando presente, quantificar o grau de dependência espacial, por meio do ajuste do semivariograma. $\mathrm{O}$ ajuste dos modelos de semivariograma foi com base no método dos Mínimos Quadrados Ordinários (OLS - ordinary least square), e os critérios para seleção do melhor modelo foram: i) menor valor da Soma de Quadrado de Resíduo (SQR); ii) Maior valor do coeficiente de determinação do ajuste $\left(\mathrm{R}^{2}\right)$; e iii) Maior valor do coeficiente de correlação da validação cruzada (r). Os ajustes dos modelos foram realizados com auxílio do software GS+ 7.0 (25).

A partir dos modelos ajustados foram estimados os parâmetros denominados efeito pepita $\left(\mathrm{C}_{0}\right)$, patamar $\left(\mathrm{C}_{0}+\mathrm{C}\right)$ e alcance $(\mathrm{A})$. Com base nos parâmetros desse modelo foi calculado o índice de dependência espacial (IDE) utilizando-se a expressão: $\left[\mathrm{C} /\left(\mathrm{C}_{0}+\mathrm{C}\right)\right]^{*} 100$. A dependência espacial foi classificada conforme proposto por Zimback (30), onde a dependência espacial é fraca (IDE $\leq 25,0 \%$ ), moderada $(25,0 \%<\mathrm{IDE} \leq 75,0 \%)$ e forte (IDE $>75,0 \%)$.

Para o mapeamento da incidência foi utilizada a ferramenta krigagem indicativa (17). Foi utilizado o programa Sufer 8.0 (11) para gerar os mapas de distribuição espacial das plantas doentes na lavoura.

\section{RESULTADOS E DISCUSSÃO}

Visto a epidemia de "vira-cabeça" na lavoura de tomate, ao longo do tempo, houve aumento do número de plantas doentes e aos 77 DAP $100 \%$ das plantas apresentavam sintomas (Tabela 1). Proporcionalmente ao número de plantas doentes, ocorreu aumento da área afetada ao longo do tempo (Tabela1).

Aos 57 DAP foi identificada a doença, e 19\% dessas já estavam infectadas, ocupando $16 \%$ da área da lavoura. Aos 67 DAP, ou seja, apenas 10 dias de duração da epidemia, 66\% das plantas já apresentavam sintomas da doença (Tabela1). À partir da primeira 
Tabela 1. Número de tomateiros (Solanum lycopersicum L.) com sintomas de "vira-cabeça", percentual da área afetada e taxa (dy/ dt) de progresso da epidemia da doença ao longo do tempo. Itapina, Espírito Santo - Brasil

\begin{tabular}{lccccc}
\hline Variável & \multicolumn{5}{c}{ Tempo (em dias) } \\
\cline { 2 - 6 } & $\mathbf{5 7}$ & $\mathbf{6 2}$ & $\mathbf{6 7}$ & $\mathbf{7 2}$ & $\mathbf{7 7}$ \\
& DAP $^{\mathrm{a}}$ & $\mathbf{D A P}$ & DAP & DAP & DAP \\
\hline $\mathrm{N}^{0}$ de plantas sintomáticas & 19 & 44 & 66 & 90 & 120 \\
\% da área afetada & 16 & 36 & 55 & 75 & 100 \\
Taxa (dy/dt) & 16 & 20 & 19 & 20 & 25 \\
\hline
\end{tabular}

${ }^{a}$ Dias após o transplantio; ${ }^{b}$ Número de plantas sintomáticas/dia

detecção da doença, foram necessários apenas 20 dias para ocorrência generalizada nos tomateiros dessa lavoura (Tabela1).

Apesar do aumento do número de plantas doentes, a taxa de progresso da doença foi similar entre as avaliações até $72 \mathrm{DAP}$ (Dy/Dt $=4,7$ plantas doentes/dia) (Tabela1). A partir daí, a taxa de progresso foi de 6 plantas doentes/dia, e 100\% das plantas foram infectadas. Esse aumento da taxa de progresso aos 72 DAP foi relacionado ao potencial de inóculo na área, pois nessa época $75 \%$ das plantas já apresentavam sintomas da doença (Tabela1).

Houve dependência espacial forte da distribuição das plantas de tomateiro com sintomas de "vira-cabeça" (Tabela 2). O modelo exponencial foi ajustado aos dados das avaliações realizadas aos $57 \mathrm{e}$ 62 DAP, e o modelo esférico para as demais avaliações (67 e 72 DAP) (Tabela 2).

O maior valor do alcance foi de 4,3 $\mathrm{m}$ aos $57 \mathrm{DAP}$, reduzindo ao longo do tempo e proporcionalmente ao aumento do número de plantas infectadas (Tabela 2). Também houve redução no valor do efeito pepita e dos resíduos do modelo, bem como aumento do valor do patamar ao longo do tempo (Tabela 2).

Comprovado a dependência espacial para ocorrência "vira-cabeça" em lavoura de tomateiro, foi gerada uma malha interpolada, ou mapas da distribuição espacial para visualizar a distribuição espacial, e o progresso ao longo do tempo (Figura 1).

Quanto à localização espacial das plantas doentes, não houve concentração em setores específicos da malha (Figura 1). Assim, aos 57 DAP houve distribuição aleatória das plantas doentes na forma de focos ou pequenos grupos. No entanto, ao longo do tempo surgiram focos secundários da doença, expansão lateral e coalescência desses, e o padrão de distribuição espacial foi agregado até os 72 DAP. Posteriormente aos 77 DAP, o padrão de distribuição da doença foi regular em toda lavoura (Figura 1).

Foi possível demonstrar o potencial de danos do "vira-cabeça" na cultura do tomateiro cultivado na região norte do Estado do Espirito
Santo. No Brasil existem exemplos de danos e perdas em diversas culturas agrícolas e ornamentais relacionadas à tospoviroses $(5$, 9, 10, 12, 22, 23). Fajardo et al. (5) verificaram 84,4\% de redução na produção total e de $96,3 \%$ na produção comercial por planta de tomateiro industrial infectado por TSWV. Na cultura da alface e do pimentão também já foram relatados danos na proporção de $100 \%$ e $69 \%$, respectivamente, devido à infecção por TSWV (22).

Além do potencial de dano, a epidemia do "vira-cabeça" foi caracterizada por elevadas taxas de progresso ao longo do tempo, conforme também verificado por Silva et al. (27) para a cultura do fumo no Estado de Alagoas - Brasil. Após detecção das primeiras plantas com sintomas, aproximadamente 5 plantas saudáveis se tornaram doentes a cada dia. Assim a epidemia evoluiu rapidamente e, a partir de $19 \%$ de plantas doentes (fontes de inóculo), em apenas 20 dias houve doença em $100 \%$ das plantas, inviabilizando a produção econômica da lavoura. Gomes et al. (12) também relataram perda de stand e produção de frutos não-comercializáveis na proporção de $32,5 \%$, quando a lavoura apresentava $23,18 \%$ de plantas com sintomas.

Essa elevada taxa de progresso da epidemia caracteriza ação de algum agente vetor associado às fontes de inóculo na área. De fato, TSWV tem como principal vetor espécies de tripes, sendo as principais F. schultzei e F. occidentalis $(5,26,27)$. Esses apresentam relação vírus/vetor do tipo circulativa/propagativa, tornando o vetor apto a transmitir o vírus por toda a sua vida. Dessa forma, o vetor pode migrar e transmitir o patógeno para plantas sadias a curtas e longas distâncias, com eficiência e de forma rápida $(5,29)$, conforme verificado nesse estudo. Além disso, nos cultivos de verão, conforme foi o presente estudo, quando os meses são quentes e úmidos, ocorre aumento da população do vetor e, consequentemente, a frequência da virose (2, 12). Este aumento progressivo da incidência da doença também pode estar associado aos tratos culturais indispensáveis à cultura, como por exemplo, o desbaste (16).

No presente estudo, essa disseminação do patógeno foi favorecida em razão do elevado número de focos iniciais da doença, ou fontes de inóculo do vírus, dentro da própria lavoura quando a epidemia começou. Além da expansão dos focos iniciais e aumento do número de plantas doentes, surgiram novos focos ao longo do tempo. Nesse caso, plantas daninhas hospedeiras do vírus presentes nas entrelinhas da cultura, na mesma localidade e/ou de região produtores distantes, também podem ter contribuído como fonte de inóculo $(4,5,20)$. Foi possível identificar focos da doença no interior da lavoura e também nas bordas. Assim, conforme concluíram Camann et al. (3) para a cultura do amendoim, na lavoura de tomateiro a distribuição de TSWV no campo de cultivo foi relacionada tanto ao movimento dentro do campo, como também da imigração do vetor.

Houve disseminação do patógeno na lavoura e dependencia

Tabela 2. Parâmetros de modelos de semivariogramas referente à ocorrência e distribuição de tomateiros (Solanum lycopersicum L.) com sintomas de "vira-cabeça" ao longo do tempo. Itapina, Espírito Santo - Brasil

\begin{tabular}{lcccc}
\hline Parâmetros & \multicolumn{3}{c}{ Incidência (DAP) $^{1 /}$} \\
\cline { 2 - 5 } & 57 DAP & 62 DAP & 67 DAP & Esférico \\
\hline Modelo & Exponencial & Exponencial & 0,0063 & 0,0074 \\
$\mathrm{C}_{0}{ }^{2 /}$ & 0,027 & 0,019 & 0,143 & 0,129 \\
$\mathrm{C}_{0}+\mathrm{C}^{3 /}$ & 0,126 & 0,151 & 1,71 & 0,69 \\
$\mathrm{a}^{4 /}(\mathrm{m})$ & 4,3 & 2,22 & 0,0008 & 0,0012 \\
$\mathrm{SQR}^{5 /}$ & 0,0014 & 0,0010 & 95,6 & 94,3 \\
$\mathrm{IDE}^{6 /}(\%)$ & 78,2 & 86,9 & \\
\hline
\end{tabular}

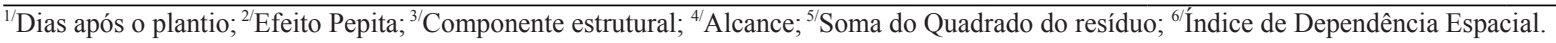




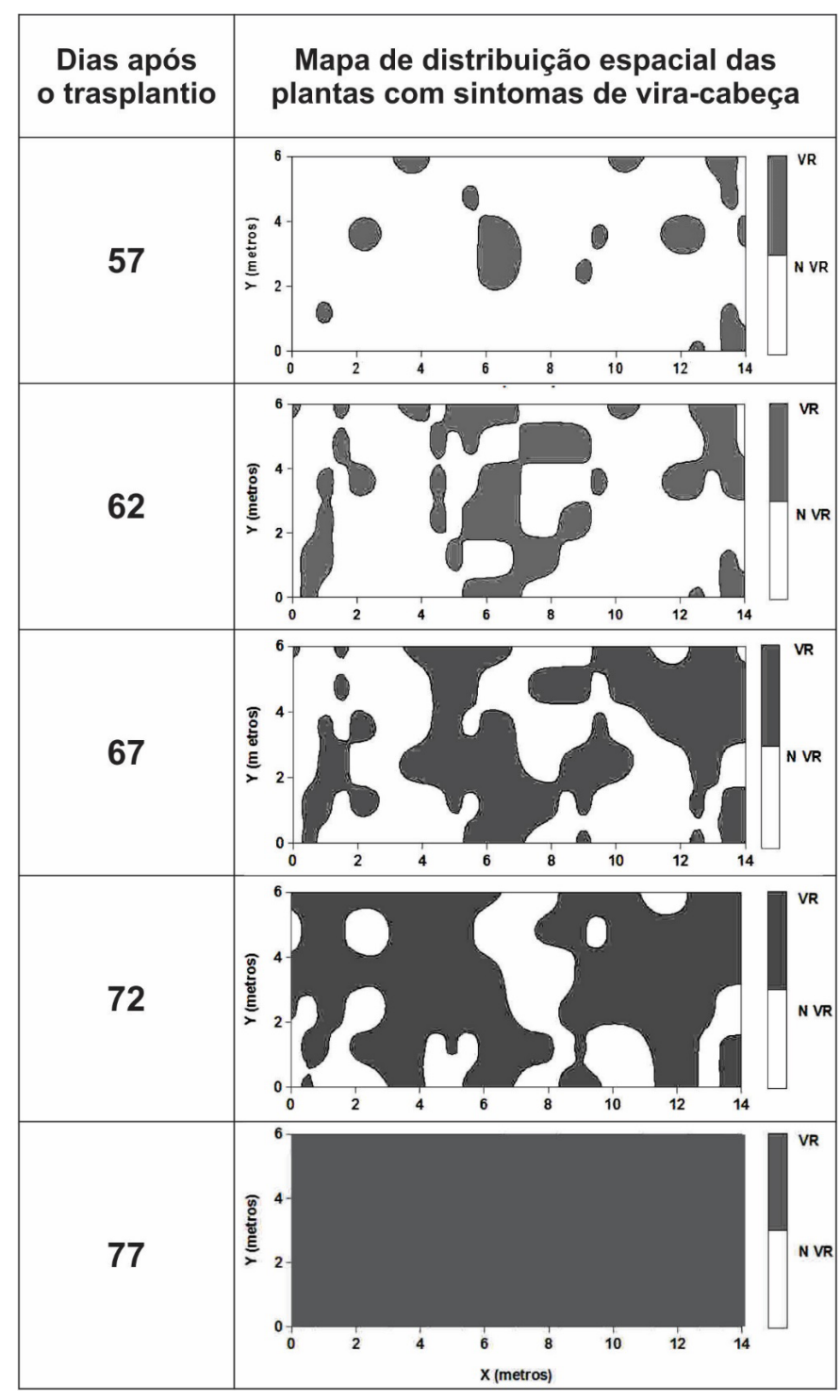

Figura 1. Mapas de krigagem da ocorrência e distribuição de tomateiros (Solanum lycopersicum L.) com sintomas de "vira-cabeça” (Tospovirus) ao longo do tempo. Itapina, Espírito Santo - Brasil. VR: Tomateiros com sintomas de "vira-cabeça"; NVR: Tomateiros assintomáticos.

espacial quanto à distribuição das plantas doentes. Nesse caso, uma planta ou um grupo de plantas infectadas funcionou como fonte de inóculo para plantas vizinhas localizadas a distâncias desde 1,69 até 4,3 m de distância. No início da epidemia a distância sob influência de determinado foco foi maior, pois o número de focos era menor e predominavam as plantas sadias. Porém à medida que aumentou $\mathrm{o}$ número de focos de plantas doentes, bem como coalescência e aumento do tamanho desses focos, a distância sob influência foi reduzida, ou seja, tendendo à uniformidade da distribuição das plantas doentes aos 77 DAP. Da mesma forma, Fajardo et al. (5) verificaram gradiente de distribuição das plantas de tomateiro com sintomas de "vira-cabeça", à medida que se distanciava da fonte de inóculo. Alves et al. (1) também verificaram formação e coalescência de focos secundários para o patossistema C. lindemuthianum na cultura do feijoeiro (Phaseolus vulgaris L.). Esse aumento do número de focos do "vira-cabeça" ao longo do tempo proporcionou também aumento do valor de semivariância (componente estrutural) e redução no valor do alcance, assim como relatado por Noetzold et al. (24) para o patossistema Colletotrichum truncatum na cultura da soja (Glicyne max L.).

O índice de dependência espacial da distribuição das plantas doentes foi classificado como forte em todas as avaliações, com valores variando de 78,2 a 95,6\%. Os resultados apresentados por Fajardo et al. (5) também caracterizaram forte dependência espacial dessa doença, pois relataram maior intensidade da doença e dos danos à produção nas plantas mais próximas da fonte de inóculo, e que foram infectadas precocemente. Larkin et al. (18) e Alves et al. (1) em estudos com a ramulose (Colletotrichum gossypii South. var. cephalospiorioides) do algodoeiro e antracnose (C. lindemuthianum) do feijoeiro, também verificaram que o índice de dependência espacial aumentou com o tempo. De acordo com esses autores, isso está relacionado ao fato que plantas sadias ficaram doentes ao longo do tempo, ou seja, houve epidemia e progresso da doença.

Ao longo da epidemia o padrão aleatório de distribuição da doença evoluiu para agregado, e posteriormente regular. Essa dinâmica populacional já foi relatada para diversas doenças viróticas em culturas agrícolas cujos agentes etiológicos são transmitidos por vetores como é o caso do "vira-cabeça" $(13,27)$. Nesse caso, a análise geoestatística, os modelos exponencial e esférico, e os mapas de krigagem possibilitaram caracterizar e assim entender o padrão de distribuição do "vira-cabeça" do tomateiro ao longo do tempo.

Nesse estudo a incidência do "vira-cabeça" na cultura do tomateiro foi mapeada no espaço e ao longo do tempo. Houve elevada taxa de progresso da doença e capacidade de disseminação do patógeno à partir dos focos iniciais, caracterizando o potencial de danos à cultura quando existe inóculo na área e as condições ambientais são favoráveis ao vetor. Esse incremento do desenvolvimento da doença também está relacionado ao contínuo influxo de inóculo primário de tripés virulífero (26). Logo, as principais medidas de manejo que reduzem o inóculo inicial do patógeno, como por exemplo o "rouguing" e eliminação de plantas hospedeiras silvestres, plantio em áreas distantes de plantas infectadas e enfestadas com o vetor, plantio de mudas sadias, cultivares resistentes e controle do vetor, podem ser eficientes dentro de um programa de manejo integrado $(21,26)$.

Desta forma, podemos concluir que: aos 57 DAP foi detectada a doença em 16\% das plantas, distribuídas aleatoriamente na forma de focos; houve epidemia da doença na lavoura de tomate, e a taxa de progresso (Dy/Dt) variou de 4,7 a 6 plantas doentes/dia, e 100\% das plantas apresentaram sintomas aos 20 dias após a primeira detecção da doença na lavoura; houve dependência espacial forte da distribuição das plantas de tomateiro com sintomas de "vira-cabeça" em todas as avaliações; ao longo do tempo surgiram focos secundários da doença, expansão lateral e coalescência desses, caracterizando dispersão por ação do agente vetor associado às fontes de inóculo inicial; o padrão aleatório de distribuição da doença evoluiu para agregado, e posteriormente regular e foi possível demonstrar o potencial de danos do "vira-cabeça" na cultura do tomateiro no Estado do Espirito Santo.

\section{REFERÊNCIAS}

1. Alves, M.C.; Pozza, E.A.; Machado, J.C.; Araújo, D.V.; Talamini, V.; Oliveira, M.S. Geoestatística como metodologia para estudar a dinâmica espaço-temporal de doenças associadas a Colletotrichum spp. transmitidos por sementes. Fitopatologia Brasileira, Brasília, v.31, n.6, p.557-563, 2006.

2. Ávila, A.C.; Inoue-Nagata, A.K.; Costa, H.; Boiteux, L.S.; Neves, L.O.D.Q.; Prates, R.S.; Bertini, L.A. Ocorrência de viroses em tomate e pimentão na região serrana do estado do Espírito Santo. Horticultura Brasileira, 
Brasília, v.22, n., p.655-658, 2004.

3. Camann, M.A.; Culbreath, A.K.; Pickering, J.; Todd, J.W.; Demski, J.W. Spatial and temporal patterns of spotted wilt epidemics in peanut. Phytopathology, Salinas, v.85, n.8, p.879-885, 1995.

4. Chappell, T.M.; Beaudoin, A.L.; Kennedy, G.G. Interacting virus abundance and transmission intensity underlie tomato spotted wilt virus incidence: an example weather-based model for cultivated tobacco. PloS One, San Francisco, v.8, n.8, p.e73321, 2013.

5. Fajardo, T.M.V.; Lopes, C.A.; Silva, W.L.C.; Ávila, A.C. Dispersão da doença e redução da produção em tomateiro industrial infectado por tospovírus no Distrito Federal. Fitopatologia Brasileira, Brasília, v.22, n.3, p.413-418, 1997.

6. FAO. Crop statistics are recorded for 173 products, covering the following categories. Rome, Italy, 2016. Disponível em: <http://faostat.fao.org/ site/567/\%20default.aspx\#ancor>. Acesso em: 12 set. 2016.

7. Fernandes, F.R.; Albuquerque, L.C.; Britto Giordano, L.; Boiteux, L.S.; Ávila, A.C.; Inoue-Nagata, A.K. Diversity and prevalence of Brazilian bipartite begomovirus species associated to tomatoes. Virus Genes, Munique, v.36, n.1, p.251-258, 2008.

8. Ferraz, E.; Resende, L.V.; Lima, G.S.A.; Silva, M.C.; França, J.G.E.; Silva, D.J. Redenção: nova cultivar de tomate para a indústria resistente a geminivírus e tospovírus. Horticultura Brasileira, Brasília, v.21, n., p.578-580, 2004.

9. Giampan, J.S.; Rezende, J.A.M.; Piedade, S.M.D.S. Danos causados pelo Zucchini lethal chlorosis virus (ZLCV) sobre a produção de frutos comerciais de abobrinha de moita'Caserta'. Summa Phytopathologica, Botucatu, v.35, n.3, p.223-225, 2009.

10. Gioria, R.; Brunelli, K.R.; Kobori, R.F.; Kobori, M.M.R.G.; Rezende, J.A.M.; Kitajima, E.W. First report of Tomato spotted wilt virus (TSWV) infecting Campanula medium in Brazil. Summa Phytopathologica, Botucatu, v.36, n.2, p.176-177, 2010.

11. Golden Software INC. Surfer: Surface mapping system. Version 8.00. Golden, 2002.

12. Gomes, F.B.; Fortunato, L.J.; Pacheco, A.L.V.; Azevedo, L.H.; Freitas, N.; Homma, S.K. Incidência de pragas e desempenho produtivo de tomateiro orgânico em monocultivo e policultivo. Horticultura Brasileira, Brasília, v.30, n.4, p.756-761, 2012.

13. Gottwald, T.R.; Cambra, M.; Moreno, P.; Camarasa, E.; Piquer, J. Spatial and temporal analyses of citrus tristeza virus in eastern Spain. Phytopathology, Salinas, v.86, n.1, p.45-55, 1996.

14. Instituto Brasileiro de Geografia e Estatística - IBGE. Dados de Previsão de Safra: Produção - Unidade da Federação: 1. Brasília, 2016.

Disponível em: < http://www.sidra.ibge.gov.br/bda/prevsaf/default.asp?$\mathrm{t}=1 \& \mathrm{z}=\mathrm{t} \& \mathrm{o}=26 \& \mathrm{u} 2=1 \& \mathrm{u} 3=1 \& \mathrm{u} 4=1 \& \mathrm{u} 1=29>$. Acesso em: 12 set. 2016.

15. Kimati, H.; Amorim, L.; Bergamin Filho, A.; Camargo, L.E.A., Rezende, J.A.M. Manual de fitopatologia: doenças das plantas cultivadas. Piracię caba: Agronômia Ceres, 1997. v.2, 774p.

16. Krishna Kumar, N.K.; Ullman, D.E.; Cho, J.J. Evaluation of Lycopersicon germ plasm for tomato spotted wilt tospovirus resistance by mechanical and thrips transmission. Plant Disease, Ames, v.77, n.9, p.938-941, 1993.

17. Landim, P.M.B. Análise estatística de dados geológicos. 2.ed. São Paulo: Unesp, 2003. 254p.

18. Larkin, R.P.; Gumpertz, M.L.; Ristaino, J.B. Geostatistical analysis of Phytophthora epidemic development in commercial bell pepper fields Phytopathology, Salinas, v.85, n.2, p.191-202, 1995.

19. Loos, R.A.; Silva, D.D.; Fontes, P.C.R.; Picanço, M.C.; Gontijo, L.M.; Silva, E.; Semeão, A.A. Identificação e quantificação dos componentes de perdas de produção do tomateiro. Horticultura Brasileira, Brasília, v.22, n.2, p.238-242, 2004.

20. Macharia, I.; Backhouse, D.; Wu, S.B.; Ateka, E.M. Weed species in tomato production and their role as alternate hosts of Tomato spotted wilt virus and its vector Frankliniella occidentalis. Annals of Applied Biology, Newport, v.169, n.2, p.224-235, 2016.

21. Matos, E.S.; Siqueira, W.J.; Lourenção, A.L.; Melo, A.M.T.; Sawazaki, H.E.; Souza-Dias, J.A.C.; Colariccio, A. Resistência de genótipos de tomateiro a um isolado de geminivírus do cinturão verde de Campinas, São Paulo. Fitopatologia Brasileira, Brasília, v.28, n.2, p.159-165, 2003.

22. Moraes, G.J.; Wanderley, L.J.; Costa, A.S. Surto de vira-cabeca na cultura de alface em Pernambuco. Horticultura Brasileira, Brasília, v.6, n. p.24-25, 1988

23. Nagata, T.; De Ávila, A.C.; Tavares, P.C.T.M.; Barbosa, C.J.; Juliatti, F.C.; Kitajima, E.W. Occurrence of different tospoviruses in six states of Brazil. Fitopatologia Brasileira, Brasília, v.20, n., p.90-95, 1995.

24. Noetzold, R.; Alves, M.D.C.; Cassetari Neto, D.; Machado, A.Q. Spatial variability of Colletotrichum truncatum in soybean field under three seed health levels. Summa Phytopathologica, Botucatu, v.40, n.1, p.16-23, 2014.

25. Robertson, G. Gs+: geostatistics for the environmental sciences gamma design software. Michigan: Plainwell, 2000.

26. Silva, J.N.; Michereff, S.J.; Pio-Ribeiro, G.; Andrade, G.P. Arranjo espacial do vira-cabeça do fumo em Arapiraca, Estado de Alagoas. Fitopatologia Brasileira, Brasília, v.26, n., p.721-725, 2001.

27. Silva, J.N.E.; Michereff, S.J.; Pio-Ribeiro, G.; Andrade, G.P. Progresso do vira-cabeça do fumo em arapiraca, Estado de Alagoas. Revista Caatinga, Mossoró, v.18, n.1, p.35-40, 2005.

28. Uchôa, C.N.; Pozza, E.A.; Pozza, A.A.A.; Silva Moraes, W. Modelagem geoestatística da sigatoka-negra e sua relação com a fertilidade do solo. Bioscience Journal, Uberlândia, v.27, n.3, p.357-362, 2011.

29. Ullman, D.E.; Sherwood, J.L.; German, T.L. Thrips as vectors of plant pathogens. In: Lewis T. Thrips as crop pests. New York: CAB International, 1997. p.539-565.

30. Zimback, C.R.L. Análise espacial de atributos químicos de solos para fins de mapeamento da fertilidade do solo. 2001. 114 pág. Tese (LivreDocência)-Universidade Estadual Paulista, Botucatu. 